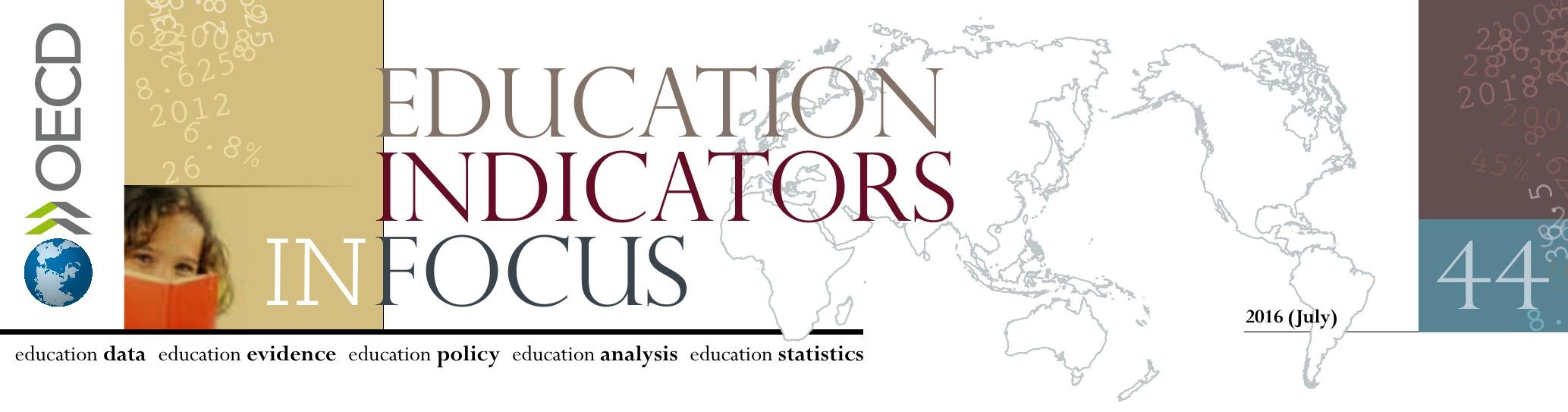

\title{
Attainment and labour market outcomes among young tertiary graduates
}

- Among 25-34 year-olds with a tertiary degree, the proportion of those who obtained at least a master's or equivalent degree varies from $4 \%$ in Chile to $79 \%$ in the Slovak Republic.

- Tertiary attainment also varies across generations: while 49\% of tertiary-educated 25-34 year-olds have a bachelor's or equivalent degree as their highest educational attainment, this falls to $39 \%$ among 55-64 year-olds.

- Employment prospects tend to improve with tertiary attainment levels: the average employment rate of 25-34 year-olds with a doctorate is $88 \%$, for those with a master's or equivalent degree it is $84 \%$ and for those with at most a short-cycle or a bachelor's degree it is around $\mathbf{8 0} \%$.

- In some countries, however, increased tertiary attainment is not associated with improved employment prospects among 25-34 year-olds, except for doctorate holders. In other countries, short-cycle tertiary graduates are more likely to be employed than those with a bachelor's degree.

Tertiary education is comprised of a diverse range of programmes. Short-cycle tertiary programmes are typically shorter and more practically-based than bachelor's or equivalent programmes, which in turn are less advanced than master's or equivalent programmes. Doctoral programmes, on the other hand, are designed primarily to lead to an advanced research qualification. The distribution of tertiary attainment across these levels, as well as their employment prospects in the labour market, varies widely from country to country.

The share of tertiary-educated people with a master's or doctoral degree varies widely from country to country.

Across OECD countries, $41 \%$ of $25-34$ year-olds have tertiary education, but the figures vary enormously from $24 \%$ in Italy to $68 \%$ in Korea. There are also very large differences in the sort of degrees tertiary-educated people have attained. On average, $15 \%$ of tertiary-educated $25-34$ year-olds have at most a short-cycle tertiary degree, $49 \%$ a bachelor's or equivalent degree, $35 \%$ a master's or equivalent degree and $2 \%$ a doctoral or equivalent degree. But in Poland and the Slovak Republic more than $70 \%$ of tertiary-educated 25-34 year-olds have at least a master's or equivalent degree, while the corresponding proportion is less than $10 \%$ in Chile, Greece and Turkey (Figure 1). Short-cycle tertiary graduates account for less than $0.5 \%$ of tertiary-educated young people in Italy, Poland and Switzerland, but for $40 \%$ or more in Austria, Canada and France.

An increasing share of tertiary-educated people are attaining a bachelor's or equivalent degree. The distribution of tertiary attainment differs not only across countries, but also across generations. Among 25-34 year-olds with tertiary education, the share of graduates with a bachelor's or equivalent degree as their highest educational attainment is 10 percentage points higher than among 55-64 year-olds, on average. This is due to a smaller share of adults in the younger age group who have at most short-cycle tertiary education. In some countries, the share of young adults with a master's or equivalent degree is also falling.

In the Czech Republic and Italy, for example, the share of tertiary graduates with a master's or equivalent degree is more than 20 percentage points lower among 25-34 year-olds than among 55-64 year-olds. In these and other European countries, long first degrees awarding a master's or equivalent qualification had been the norm in tertiary education until the Bologna Declaration in 1999. Since then, most students have had the option to finish their studies after completing a bachelor's programme, increasing the share of graduates in the population with at most a bachelor's degree. 
Figure 1. Shares of tertiary-educated 25-34 year-olds, by educational attainment

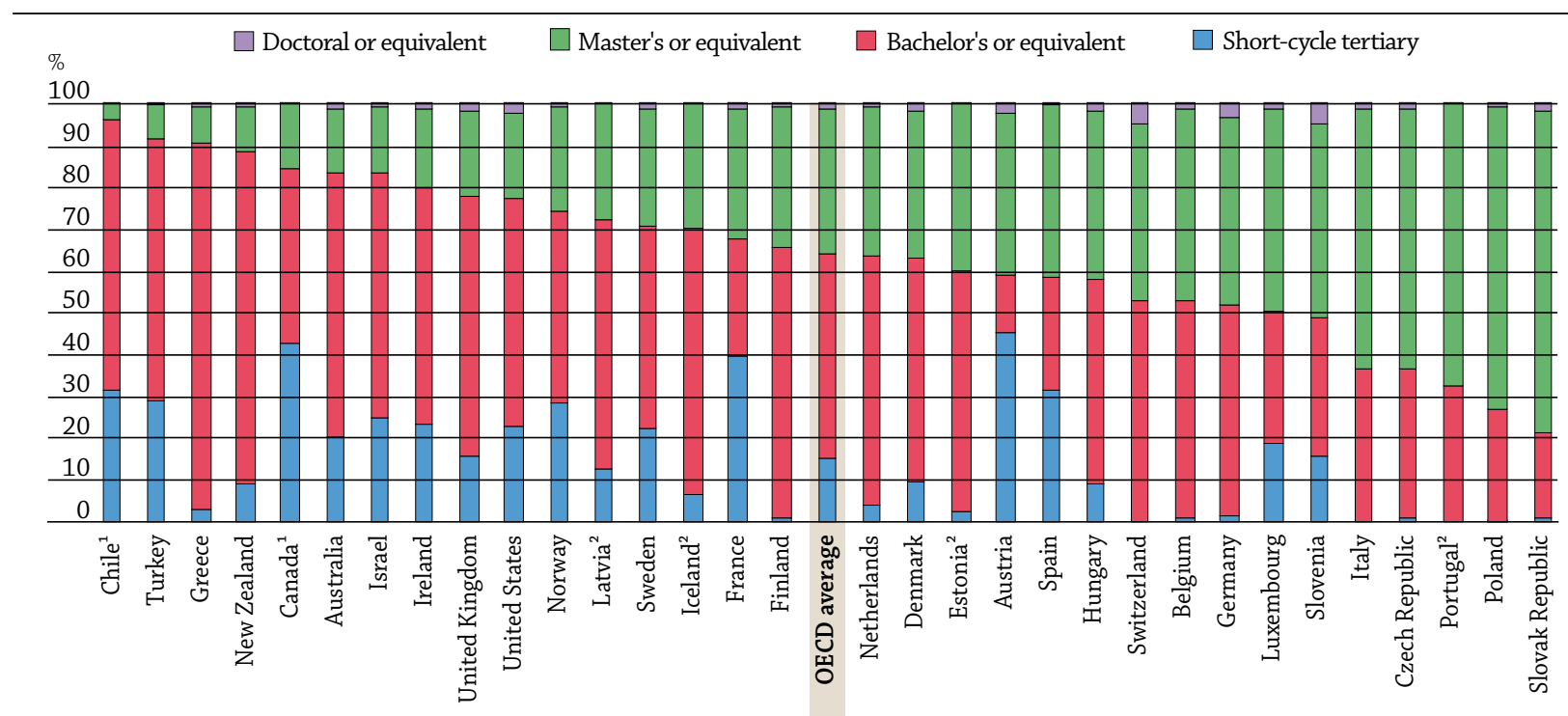

Notes:

1. The share of people with a doctoral or equivalent degree is included in the share of people with at most a master's or equivalent degree. 2. The share of people with a doctoral or equivalent degree cannot be estimated due to the small sample size. The shares reported in the figure are computed based on the total number of 25-34 year-olds with at most a short-cycle tertiary, bachelor's or master's or equivalent degrees.

Countries are ranked in descending order of the share of tertiary-educated 25-34 year-olds with at most a short-cycle or bachelor's or equivalent degree. Source: OECD (2015), "Educational attainment and labour-force status", Education at a Glance (database), http://stats.oecd.org/Index. aspx?datasetcode=EAG_NEAC. See Annex 3 for notes (www.oecd.org/education/education-at-a-glance-19991487.htm).

The share of tertiary-educated people with at most a short-cycle degree is 8 percentage points lower for 25-34 year-olds than for 55-64 year-olds, on average. In Slovenia (where the difference is 17 percentage points) this is due to the cessation of some short-cycle tertiary programmes, while in New Zealand the difference of 31 percentage points is due to the increased availability of professionally oriented programmes at the bachelor's or equivalent level. Finland presents the most striking difference (49 percentage points), as it phased out short-cycle tertiary programmes during the educational reforms in the 1990s.

\section{Doctorate holders enjoy the highest employment rates among tertiary graduates.}

Doctoral graduates have succeeded in contributing significantly to knowledge in their field of study, and are therefore in high demand for jobs which require strong academic skills. On average, 88\% of 25-34 year-olds with a doctoral degree are employed across OECD countries. This is more than adults with any other level of attainment (Figure 2). Even in the few countries where 25-34 year-olds with a doctorate have lower employment rates than those with a master's degree, the employment rate is highest among those with doctorates for all other age groups.

\section{Employment rates among 25-34 year-olds with different levels of tertiary education vary widely} across countries.

On average across OECD countries, 84\% of 25-34 year-olds with a master's or equivalent degree are employed, about five percentage points more than for those with at most a short-cycle or a bachelor's degree (Figure 2). However, there are large differences in the employment rates of 25-34 year-olds with different levels of tertiary attainment across countries.

For example, in Costa Rica, Israel, Sweden and Turkey, a more advanced tertiary qualification is always associated with higher employment rates for 25-34 year-old graduates. The highest differences in employment rates across tertiary attainment levels can be observed in Turkey: the employment rates for 25-34 year-olds with a master's degree is $87 \%$, much higher than for those with a bachelor's degree (78\%) or a short-cycle tertiary qualification (70\%).

In some other countries, including Australia, Belgium, Canada, Finland, Germany, the Netherlands, Spain and Switzerland, tertiary-educated 25-34 year-old graduates - excluding doctoral graduates - have similar employment prospects 
Figure 2. Employment rates of 25-34 year-olds with a bachelor's degree compared to those with a short-cycle, master's or doctoral qualification (2014)

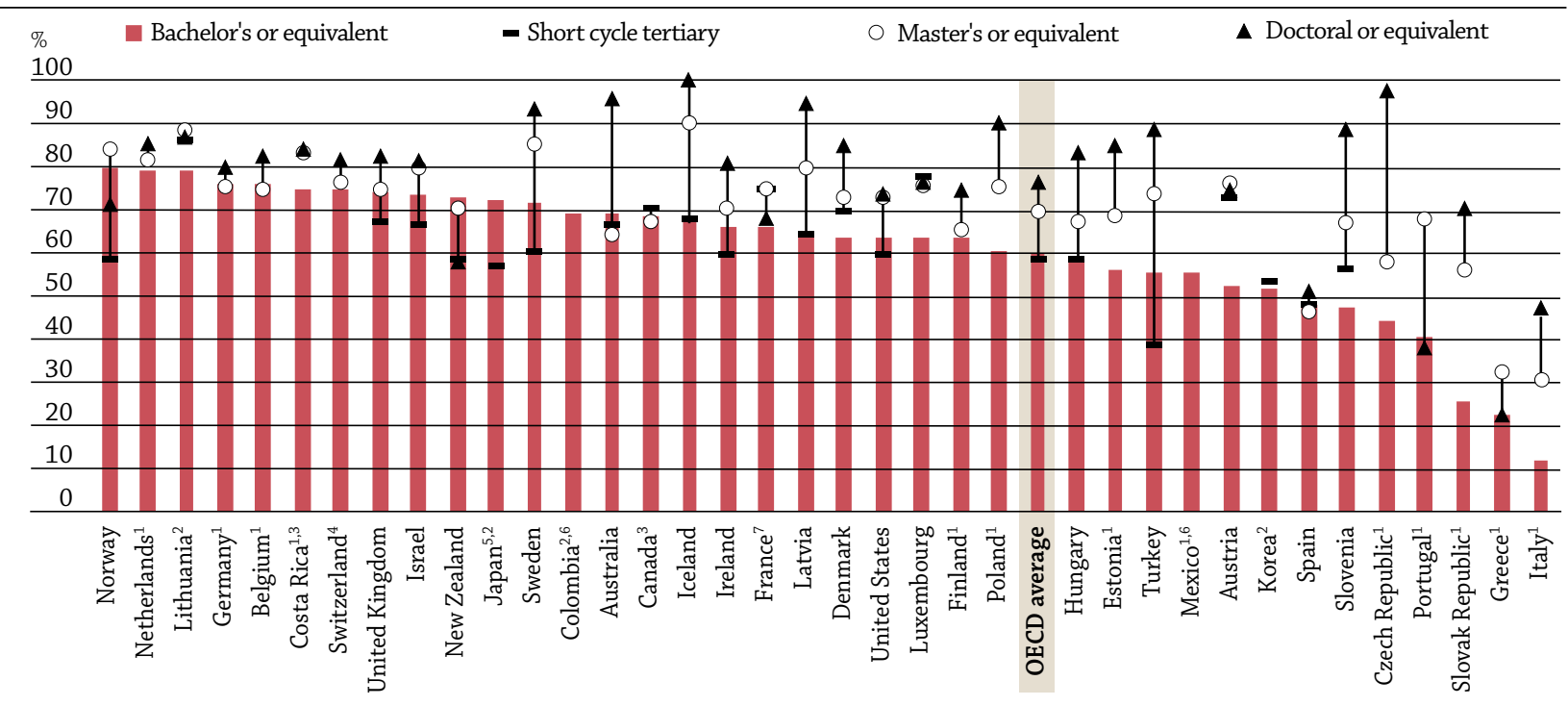

Notes:

1. The share of 25-34 year-olds with short-cycle tertiary education is less than $2 \%$ or short-cycle tertiary educational programmes do not exist and have not been shown.

2. Data for doctoral or equivalent and master's or equivalent programmes are included in bachelor's or equivalent programmes.

3. Data for doctoral or equivalent programmes are included in master's or equivalent programmes.

4. Data for short-cycle tertiary education are included in the other tertiary levels.

5. Data for short-cycle tertiary education include upper secondary and post-secondary non-tertiary programmes (less than $5 \%$ of the adults are in this group).

6. Data for short-cycle tertiary education are included in bachelor's or equivalent programmes.

7. Year of reference 2013.

Countries are ranked in descending order of the employment rate of adults with a bachelor's degree.

Source: OECD (2015), "Educational attainment and labour-force status", Education at a Glance (database), http://stats.oecd.org/Index. aspx?datasetcode=EAG_NEAC. See Annex 3 for notes (www.oecd.org/education/education-at-a-glance-19991487.htm).

regardless of the level of tertiary attainment. This does not necessarily imply that tertiary graduates in these countries face the same conditions in the labour market. For example, in Australia, although their employment rates are similar, 25-34 year-olds with a bachelor's degree earn on average 9\% more than their peers with only a short-cycle tertiary degree, and in Canada, they earn 19\% more. In Finland, in contrast, both the employment rate and the earnings of people with bachelor's and short-cycle degrees are quite similar (OECD, 2015).

In some countries, short-cycle tertiary programmes are particularly effective as a pathway into the labour market.

Despite the fact that students invest less time in short-cycle tertiary programmes than in bachelor's or equivalent ones, which are typically one to two years longer, this does not necessarily translate into lower employment rates. Figure 3 shows the difference between the employment rates of short-cycle and bachelor's graduates (the employment premium) plotted against the share of 25-34 year-old tertiary graduates who attained at most a short-cycle tertiary degree. Across all observations, there appears to be no general relationship between the two variables. For example, Turkey and New Zealand have similar, negative, employment premiums but very different proportions of short-cycle tertiaryeducated 25-34 year-olds.

However, in Austria, Canada, Korea, France and Spain, where more than 30\% of 25-34 year-old tertiary graduates have at most a short-cycle tertiary degree, the employment rates for short-cycle graduates are at least as high as for those with bachelor's or equivalent level attainment (Figure 3). In these countries, ${ }^{1}$ the employment rate among 25-34 year-old short-cycle graduates is also as high as that of master's graduates in the same age group, although master's graduates tend to earn more. These results suggests that where short-cycle tertiary programmes are well established, their educational credentials are recognised by the labour market; and conversely that where these programmes offer good employment prospects, more young people are likely to enrol in them. 
Figure 3. Share of tertiary educated 25-34 year-olds with at most a short-cycle degree and their employment premium ${ }^{1}$ compared to those with a bachelor's degree (2014)

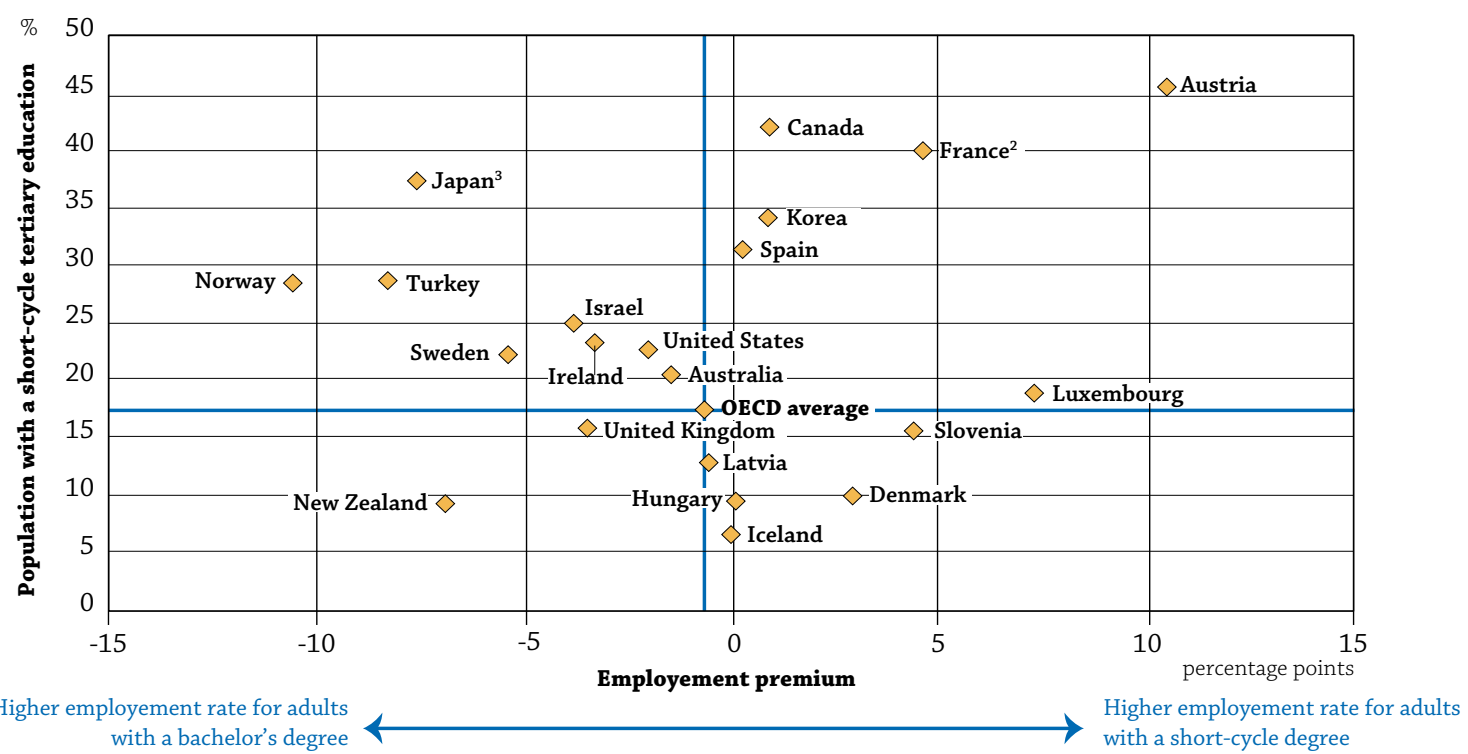

Notes: The share of 25-34 year-olds with short-cycle tertiary education is less than $2 \%$ or short-cycle tertiary educational programmes do not exist or cannot be distinguisged in Belgium, Costa Rica, the Czech Republic, Estonia, Finland, Germany, Greece, Italy, Mexico, the Netherlands, Poland, the Slovak Republic and Switzerland and have not been shown.

1. The employment premium is defined as the difference between the employment rate of young adults with a short-cycle tertiary education and those with a bachelor's degree.

2. Year of reference 2013.

3. Data for tertiary education or short-cycle tertiary education include upper secondary and post-secondary non-tertiary programmes (less than $5 \%$ of the adults are under this group).

Source: OECD (2015), "Educational attainment and labour-force status", Education at a Glance (database), http://stats.oecd.org/Index. aspx?datasetcode=EAG_NEAC. See Annex 3 for notes (www.oecd.org/education/education-at-a-glance-19991487.htm).

The bottom line: The distribution of tertiary-level attainment varies widely, both across OECD countries and across generations within a country. Among 25-34 year-olds, doctoral graduates enjoy higher employment rates than other tertiary graduates, but young bachelor's and master's degree holders are not always more likely to be employed than people with short-cycle tertiary degrees. This suggests that, regardless of their distribution of tertiary-level attainment, countries need to ensure that the qualifications awarded by the tertiary education system are recognised by the labour market.

\section{For more information}

OECD (2015), Education at a Glance 2015: OECD Indicators, OECD Publishing, Paris, http://dx.doi.org/10.1787/eag-2015-en.

\section{Contact}

Gabriele Marconi (Gabriele.MARCONI@oecd.org) and Markus Schwabe (Markus.SCHWABE@oecd.org)

\section{Visit}

www.oecd.org/education/education-at-a-glance-19991487.htm Education Indicators in Focus (previous issues)

PISA in Focus

Teaching in Focus

\section{Next topic}

Intergenerational education mobility by parental immigrant status.

Photo credit: @ Ghislain \& Marie David de Lossy/Cultura/Getty Images

This paper is published under the responsibility of the Secretary-General of the OECD. The opinions expressed and arguments employed herein do not necessarily reflect the official views of OECD member countries.

This document and any map included herein are without prejudice to the status of or sovereignty over any territory, to the delimitation of international frontiers and boundaries and to the name of any territory, city or area.

The statistical data for Israel are supplied by and under the responsibility of the relevant Israeli authorities. The use of such data by the OECD is without prejudice to the status of the Golan Heights, East Jerusalem and Israeli settlements in the West Bank under the terms of international law. 